\title{
An Exploration of Chinhoyi University Students' Perceptions of Lifelong Learning
}

\author{
Edlight Mutungwe, Maria Tsvere \\ Lecturer Chinhoyi University of Technology, Zimbabwe \\ Lecturer Chinhoyi University of Technology, Zimbabwe
}

\begin{abstract}
The research sought to establish university students' understanding of lifelong learning and how these students are influenced to be lifelong learners (LLL). A sample of 114 was randomly selected from the university's five schools. Questionnaires were distributed as data collection tools and findings analysed using SPSS. Findings revealed that respondents assumed that LLL was for working adult students housed in the Institute of Lifelong Learning. The concept of LLL is not common among people in communities and schools. Students associated LLL with learning in the confines of a classroom/lecture room and this being for adults who missed the opportunity of learning during their school days. The study established that the majority of students learnt about LLL when they came to the university and understood in principle, that LLL has no boundaries and it embraces formal, informal and non-formal education. Students were influenced to be lifelong learners through media, friends and family. The role of LLL in people's lives from the students' perspectives was the development of skills, competencies, innovation and creativity. The university should come up with a programme that orients students with issues of LLL so that students understand what LLL is all about and an awareness programme to be carried out in the schools. This programme should aim to reach out to school pupils and communities to develop the desire to learn, read and improve oneself.
\end{abstract}

Key Words: Lifelong learning, perceptions,

\section{Introduction}

According to the 1997-2007 Report on Development and state of the Art of Adult Learning in Zimbabwe, the country has the highest literacy rate in the SADC region. The 1982 population census revealed that out of four million adults, $63 \%$ (2.5million) were semi-literate. Out of these, $64 \%$ were women. This gave rise to the 1983 literacy campaign which was the starting point of the emphasis on Lifelong Learning (LLL). The 2002 census revealed a 9.08\% illiteracyrate. However, women still carried the highest number of the illiterate.

In Zimbabwe every citizen has a constitutional right to access education regardless of age, creed, raceor gender. The Education Act of 1987 as amended in 1996 and 2006 provides for Adult Education and Learning: S.1.371 of 1998 entitled the Education (Correspondence \& Independent) Regulations, 1998, the Lifelong Education Policy. These policy instruments only pertain to the Ministry of Education, Sport and Culture; other ministries have their own policies on Adult Learning and Education. The Ministry of Education,Art, Sport and Culture is the foundation for the development of a culture of Lifelong Learning, hence, requires teachers who lead by example and other ministries e.g. Higher Education support by developing degree programmes for teachers, managers in different sectors of industry and the public sector as well as research work that brings about change and innovation. Teachers after attaining degrees, then go back to their respective schools to give an education that creates innovative, creative and knowledgeable school leavers able to solve problems in society. The Presidential Commission of Inquiry into Education and Training; National Report of the Republic of Zimbabwe (1999) commonly referred to in Zimbabwe as, 'The Nziramasanga Report (1999)' noted the importance of Adult Education and Lifelong Learning in Zimbabwe's Developmental Plan. It is this paper's intention to explore university students' perceptions of lifelong learning so as to identify gaps in understanding and applying lifelong learning in the development of human capital, social capital and culture capital in Zimbabwe.

\section{Statement Of The Problem}

While the country enjoys it's approximately 90\% literacy, according to the1997-2007 Report on Development and State of the Art of Adult Learning in Zimbabwe, there are so many misconceptions about Lifelong Learning among people in the different generations in Zimbabwe. Compounded with these misconceptions are the continuous strikes by teachers hampering formal learning, that's eroding the milestones in achieving education for all. The studysought to explore students' perceptions of Lifelong Learning, in the context of a university of technology in an attempt to clear misconceptions about professionals who enroll in 
universities for further studies, who are regarded as lifelong learners by students enrolling directly from high school.

\section{Justification}

This study is important as it attempts to get students perceptions on lifelong learning; an initiative developed to continuously upgradepeople's skills and competenciesin the different sectors of the economy including university graduates, especially in developing countries like Zimbabwe. Chinhoyi University of Technology (CUT) has an Institute of Lifelong Learning and will benefit from the findings of this research to improve students' attitudes and behavior toward lifelong learning. Schools are also set to benefit as the research would help the education institutions to redirect their teaching, from preparation of schemes/ course outlines, teaching, teacher/ lecturer self-presentation to students, in an attempt to instill a culture of lifelong learning (being exemplary) and to meet the demands of lifelong learning even in technology related areas. The research will set a platform for networking with other universities in strategising the implementation of lifelong learning in Zimbabwe, the region and internationally. These interactions will result in an increase in human, social and culture capital.

\section{Research Questions}

1. What is the university students' understanding of lifelong learning?

2. What is the role of lifelong learning in a university of technology and in people's lives, from the students' perspective?

3. How are students influenced to be lifelong learners during their university life?

4. What are students' suggestions on promoting lifelong learning in the university and Zimbabwe at large?

\section{Literature Review}

The concept of Lifelong Learning has been on international debates and developments for some time and the late Swedish Prime Minister Mr. Olaf Palme is known to have presented the first proposal for the implementation of Lifelong Learning while he was Minister of Education. This was at the European Education Ministers' meeting in Versailles in 1969 (Bengtsson, J 2009). The basic objectives for lifelong learning were to reduce educational disparities between the older and younger generations in favour of the older ones, to strengthen the efficiency of the labour market and the economy, and to improve co-ordination vertically between different educational levels (primary, secondary, tertiary and higher education).

Lifelong Learning has many definitions. Brahim (2007) noted that Lifelong Learning (LLL) is not understood by many including those in higher offices and academically learned. Most people, especially university students straight from high school, separate themselves from LLL. The goal of this research was, to examine how university students perceive LLL, whether they themselves are LL learners and whether this concept of LLL is linked/ related to institutions of technology.

Mentkowski and Doherty(1984:5) and Mentkowski (1988:115) refer to LLL as learning to learn, Falk and Dierking (2002:6) call it free learning and Banta (1993) calls it self-sustaining learning. Observations are that LLL has become the new metaphor for learning and uses different ways of learning. Active and independent learning seems to characterise most LLL and is most relevant in areas where new technologies are developed and the old technology becomes obsolete. An attempt to answer this question will be made in this paper from a student's perspective. Lifelong Learning is life long, life wide, voluntary and self-motivated pursuit of knowledge for either personal or professional reasons. It enhances social inclusion, active citizenship, personal development, competitiveness and employability. This learning shows that learning is not confined to childhood or the classroom but also takes place throughout life and in different situations. And, due to technology can be outside the classroom but through e-learning. Acquisition of knowledge is no longer confined to a particular school/place and time; it's ongoing as we interact with people, objects and all in the environment. Lundmark (2002:325) identified learning settings for LLL as schools, workplace and free choice venues and these three synergise to reinforce and contextualise what is learned. It can be as a response to policies and changing times. Formal learning may not have been or may not be adequate to sustain one's life hence the need for LLL, as the world changes constantly- traditional institutions have changed, economics have changed so has knowledge (technological advancement calls for adaptation which comes through LLL). Day (1998) recognises the role teachers play in inculcating LLL in formal teachings, while at the same time realising the need for teachers to practice LLL in order to develop themselves as well, hence Chinhoyi University has responded to that need by introducing a Bachelor of Technology Education degree for secondary school teachers and college lecturers. Realising this, teachers need be role models in LLL (as a must) so that this is transferred to learners who are preservers and transmitters of LLL to the next generation. The message to be conveyed to the young and old is that,' it is never too late to learn'. So the learners will encourage others in their various communities 
and they themselves will continue to learn after formal education. Establishing a culture of lifelong learning is important to develop economies, knowledge basis and boost self-esteem.

Bengtsson (2009:3)noted that the concept of LLL was put back on the policy agenda for public education(OECD, 1996) by the European Ministers of Education, because they started to understand the dramatic changes in the global economy where countries started to compete with skills and competencies, and where skills from the front-end model of education quickly became obsolete. It is evident that for technology to develop, education should respond favourably in addressing the changes starting from eradicating illiteracy then focus on equipping people with skills to adapt to change. The 1990s was a period when new technologies entered forcefully into process and product innovations at the enterprise level and many were caught unaware (the computers versus computer illiteracy) Many in Zimbabwe were forced to go back to school or be laid off, so as to fit into the world of computers. Presently, cell phones have stormed people's lives and learning to use the gadgets is a must for most people especially the young. More sophisticated cell phones are coming onto the market e.g. iPhones, iPods etc.

$\operatorname{OECD}(2001 \mathrm{a}, 2007 \mathrm{a})$ cited in Bengtsson(2009) noted that in coming up with strategies for implementation of LLL, the planning should address the education system to allow it to have content and pedagogical approaches that would fit the evolution of the learner's need over his/her life cycle. Consideration of where human, social and cultural capitals are best formed over the individual's life cycle is critical. In most cases, planners tend to dwell more on human capital formation at the expense of social and cultural capitals, as observed by Bengtsson (2009). Human capital is the set of skills which an employee acquires on the job, through training and experience and which increase production. Chinhoyi University of Technology imparts knowledge, skills and exposes its students for 8 months on attachment to have hands on experience in the various sectors of the job market. When they leave university, the graduates are more confident to work as they will have developed social and cultural capital during interactions with different people at different levels in industry, college and the home environments. Social capital is explained as an instantiated informal norm that promotes cooperation between two or more individuals, according to Fukuyama (1999). The norms that constitute social capital can range from a norm of reciprocity between two friends, all the way to complex doctrines of Christianity. Social capital is associated with trust, networks, civil society. These must lead to cooperation in groups which are related to honesty, reliability and keeping commitments. A valuable employee should have skills as well as afore mentioned qualities to be an asset to the employer, otherwise skills only do not make a wholesome being. To this, add cultural capital, which is one's accumulated knowledge in society e.g. dressing, talking, manners, preferences and orientations and it is cultural knowledge convertible into social and economic advantage,(Bourdieu 1986). Barret (1998) observed that individuals have personalities but groups of individuals have cultures. Business requires that organisations distinguish themselves through organisational culture. Individuals who come to work in an organisation should align their values so that there is organisational effectiveness. They should have shared values to achieve the best they can for the organisation's success. Thus, we also develop a culture of learning in our students for them to develop this country, a culture of innovation, designing and making and continuously upgrading one's niche also comes about through lifelong learning. But because culture is dynamic, lifelong learning becomes vital to expose employee to new aspects of organisational culture.

"To learn one set of skills at school and university is no longer enough for an individual's performance in working life", observed Bengtsson (2009). The basic skill that teachers and lecturers should impart to learners at different levels of one's educationis the ability to learn and adapt to a new skill requirement. The concept of meta-cognition comes into play, where people are encouraged to think about thinking, which is a higher order of thinking that helps one to be a better person, (Wikipedia,online) All teachers and lecturers should develop in their students the ability to think beyond and above, what others think (thinking outside the box). Technology significantly helps in LLL as it exposes people to a lot of information, hence new skills, knowledge and abilities are developed.

The 1996 UNESCO Report of the International Commission on Education for the Twenty First Century's observationson education in Zimbabwe cited by The Nziramasanga Report of 1999,propounded that all education programmes should take into account the centrality of the teacher who implements the programmes on the ground. If the teacher doesn't understand what technology is, how can he transmit this to the learner? LLL is about continuing to learn and includes those who wish to continue to add qualifications to their previous learning and training. It also encompasses the form of learning which an individual undertakes for the purpose of self-development without restriction of time or desire for certification, according to The Nziramasanga Report (1999:540). The need for versatility, to get out of the paradigm of a one track job is important. This would help to give skills to the unemployed and the retrenched when they change or lose jobs and adjusting to new structures of changing work patterns that include timework, freelance work and combination employment. The development of a reading and learning culture in the young and adults is a challenge. OECD (2004) noted the following as reasons for poor implementation of LLL; lack of workable and 
agreed strategies for implementation, lack of coherent and equitable system of financing LLL for all so as to eliminate inequalities in accessing education and learning and lastly resistance to change among the stakeholders in the education system. Most teachers are still trained for transmitting content using teachercentred approaches that do not promote learner creativity and active participation hence need to reform teacher training to emphasise on how to teach students' to learn to learn'. Bengtsson (2009) observed that it was not enough for an individual's performance to learn one set of skills at school and university during one's working life as things constantly change. This is what Chinhoyi University attempts to respond to, focusing on technology teachers with the hope that the concept of LLL will spread to as many learners and communities as possible in the life span of the programme.

\section{Methodology}

The study was carried out at Chinhoyi University of Technology using a survey that drew its population of 1637 from first and second year degree students in the university's four Schools and one Institute. The sample was randomly drawn from all the departments in the Schools and the Institute. One hundred and forty first and second year students were randomly selected from each of the four schools and one institute i.e. School of Engineering Sciences, School of Agricultural Sciences and Technology, School of Business Sciences and the Institute of Lifelong Learning. Questionnaires were distributed and collected through the offices of Assistant Registrars and Administrative Assistants for each school and Institute. A pretest of the questionnaire was given to a group of 40 block release students in the Institute and some questions noted to be ambiguous during the pretest were rephrased.

Table 1: Questionnaire Rate of Return and distribution of respondents by gender, age and school.

$\mathrm{N}=114$

\begin{tabular}{|c|c|c|c|c|c|c|c|}
\hline School & \multicolumn{2}{|c|}{ Questionnaires } & \multicolumn{2}{|l|}{ Gender } & \multicolumn{2}{|c|}{ Age in years } & \\
\hline & Out & Returned & Male & Female & $20-25$ & $26-30$ & $31+$ \\
\hline Business Sciences & 40 & 37 & $20(17.5 \%)$ & $17(15 \%)$ & 22 & 10 & 5 \\
\hline $\begin{array}{l}\text { Agricultural } \\
\text { Engineering }\end{array}$ & 30 & 26 & $12(10.5 \%)$ & $14(12.2 \%)$ & 19 & 6 & 1 \\
\hline $\begin{array}{l}\text { Production } \\
\text { Engineering }\end{array}$ & 20 & 18 & $10(8.8 \%)$ & $8(7 \%)$ & 8 & 10 & 0 \\
\hline $\begin{array}{l}\text { Institute of } \\
\text { Lifelong Learning }\end{array}$ & 30 & 29 & $16(14.1 \%)$ & $13(11.3 \%)$ & 5 & 11 & 13 \\
\hline $\begin{array}{l}\text { Hospitality } \quad \& \\
\text { Tourism }\end{array}$ & 20 & 4 & 0 & $4(3.6 \%)$ & 4 & -0 & $0-$ \\
\hline TOTAL & 140 & $114(81.2 \%)$ & $58(50.9 \%)$ & $56(49.1 \%)$ & $\begin{array}{l}58 \\
(50.9 \%)\end{array}$ & $\begin{array}{l}37 \\
(32.5 \%)\end{array}$ & $19(16.6 \%)$ \\
\hline
\end{tabular}

Table one shows that out of 140 questionnaires distributed, 114(81.2\%) were returned leaving $18.8 \%$ unaccounted for due to students failure to return this despite repeated efforts by the researcher to have them back. Nearly fifty one percent $(50.9 \%)$ of the respondents were males and forty nine $(49.1 \%)$ were females. Half $(50.9 \%)$ of the respondents were in the $20-25$ years age range.

\section{Findings And Discussions}

The results presented are from questionnaire findings. Tables, graphs, figures and narrations are used in the presentations.

Table 2 Decision to pursue University Studies influenced by;

\begin{tabular}{|c|c|c|c|}
\hline & Frequency & Percent \\
\hline \multirow{6}{*}{ 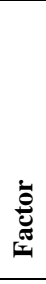 } & father & 8 & $7.0 \%$ \\
\hline & friend & 1 & $0.9 \%$ \\
\hline & government & 1 & $0.9 \%$ \\
\hline & mother & 6 & $5.3 \%$ \\
\hline & parents & 4 & $3.5 \%$ \\
\hline & self & 94 & $82.5 \%$ \\
\hline & Total & 114 & $100 \%$ \\
\hline
\end{tabular}

Ninety four respondents $(82.5 \%)$ made a personal decision to pursue university studies, while the remaining20 (17.5) were influenced by parents and friends. Parents had more influence than friends. 
Table 3: Thequestion sought to identify students coming straight from high school and those coming from the world of work/employment.

\section{Entrance to university, Work Experience Cross tabulation}

\begin{tabular}{|c|c|c|c|c|c|}
\hline \multirow{2}{*}{ Entrance to university } & \multicolumn{4}{|c|}{ Work experience } & \multirow[t]{2}{*}{ Total } \\
\hline & 0 months- $1 \mathrm{yr}$ & $2 \mathrm{yrs}$ & $3 \mathrm{yrs}$ & $4 \mathrm{yrs}$ & \\
\hline 1 From 'A' 'level & & 1 & 1 & 0 & 80 \\
\hline 2 From world of work & 2 & 11 & 18 & 2 & 33 \\
\hline Total & 80 & 12 & 19 & 2 & 113 \\
\hline
\end{tabular}

Key

1-less than two years work experience

2- 2 to 4 years working experience

3- 5 to 9 years working experience

4- 10+years working experience

Seventy eight(78) respondents entered university straight from 'A' level and have little or no work while 18 have working experience of between five and ten years. Coming to university is boosting human capital through development of social and cultural capital during attachment, and students boost these when they seek holiday employment and as they interact with those fellow students enrolling into university from industry or the job market (cross pollination).

Table 4: Students' understanding of LLL

\begin{tabular}{|c|c|c|}
\hline Selected response: Lifelong Learning is:- & Frequency & Percentage \\
\hline $\begin{array}{l}\text { 1. Learning not for 'A' level graduate at a university } \\
\text { 2. Learning for the illiterate } \\
\text { 3. Learning with no boundaries (physical, age or level) } \\
\text { 4. Learning for adults } \\
\text { 5. Learning that embraces informal, formal and non- formal } \\
\text { 6. Learning for teachers, nurses and students doing Bridging } \\
\text { mathematics } \\
\text { Total }\end{array}$ & $\begin{array}{l}7 \\
6 \\
50 \\
29 \\
19 \\
3 \\
114\end{array}$ & $\begin{array}{l}6.1 \\
5.3 \\
43.0 \\
25.4 \\
16.7 \\
2.6 \\
\mathbf{1 0 0 . 0}\end{array}$ \\
\hline
\end{tabular}

Fifty respondents $(43.9 \%)$ indicated that LLL is learning with no boundaries (physical, age or level), while 29 (25.4\% explained LLL as learning for adults and 7\% indicated LLL is not for 'A' level graduates joining university education straight from high school. It was noted that $2.6 \%$ understood LLL as learning for teachers and nurses enrolling for degree programmes in the Institute of Lifelong Learning and for students doing bridging Mathematics at the university to qualify for admission into the university programmes. A total of $35 \%$ therefore assume that LLL is for a particular group and not for all $(25.4 \%+7 \%+2.6 \%)$ confirming Brahim (2007)'s assertion that Lifelong Learning (LLL) is not understood by many. 


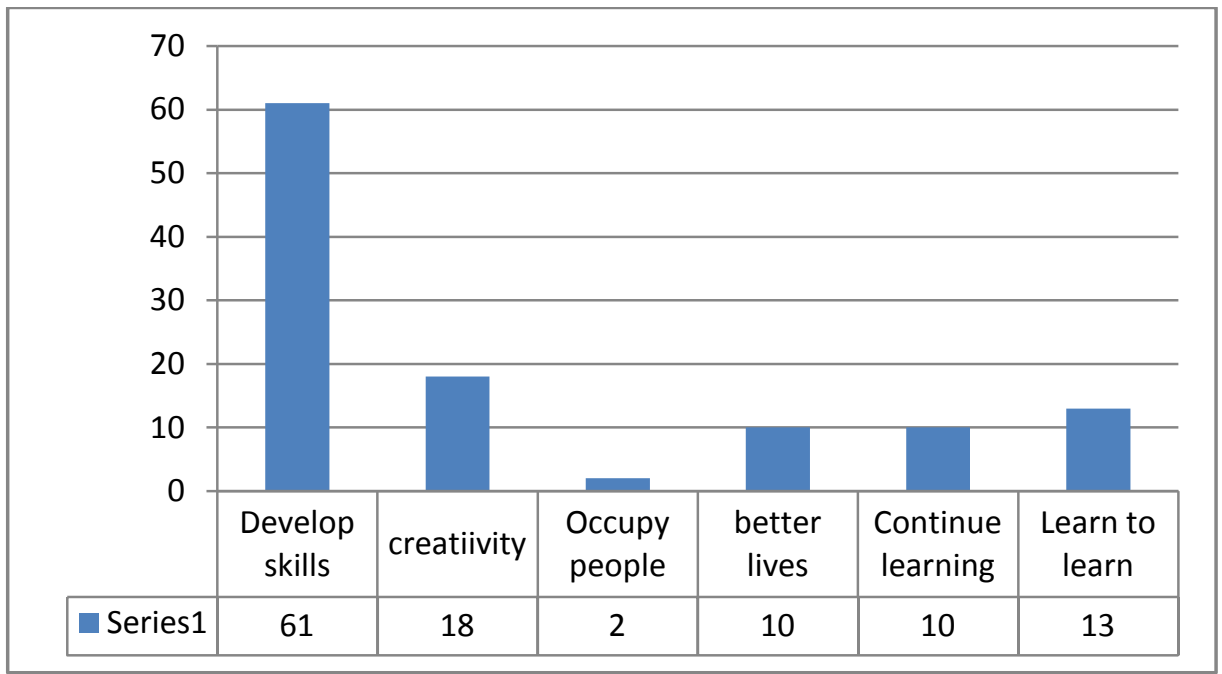

Figure 1: Role of LLL in people's life

Key Roles 1-6

1- For the development of skills and competencies

2- For innovation and creativity 18

3- To occupy people who have nothing else to do 2

4- To better people's way of life

10

5- To keep you searching for new knowledge

6- To enable citizens develop desire to learn.
61

10

Sixty one student- respondents indicated that LLL played the role of developing skills and competencies with the lowest figure of 10 identifying the role 'to better people's lives and searching for new knowledge'. This section revealed that each student had a particular role associated with LLL except for 2 who said LLL was meant to occupy people with nothing to do. Students' views on the role of LLL were alluded to by Bengtsson (2009) when he noted that skills become obsolete and need be upgraded. This was also evident in the period when computers were introduced. Technological advancement has required in-servicing and training of employees in the different sectors of economies showing that learning is a lifelong process. It is generally agreed by university students that LLL has a role in people's lives.

\section{Table 3: Responses on where students first learnt of $L L L$}

\begin{tabular}{|l|l|l|}
\hline Response & Number & Frequency \\
\hline At CUT & 92 & $81 \%$ \\
\hline At Home & 18 & $16 \%$ \\
\hline At School & 3 & $3 \%$ \\
\hline At Work place & 1 & $1 \%$ \\
\hline
\end{tabular}

Ninety two $(81 \%)$ learnt about LLL when they came to the university where there is an Institute of Lifelong Learning and through interactions with university employees while $18 \%$ learnt from home, $3 \%$ from school and $1 \%$ learnt from their workplaces. This shows that the concept of LLL is not common among people in communities and in schools as university students come from diverse backgrounds and communities.

Schools tend not to be doing much to inculcate a culture of learning, according to student's responses since, most students learnt about LLL after high school yet the basic skill that teachers and lecturers should impart to learners is the ability and interest to learn and to acquire a new skill requirement, (http://wikipedia.org/wiki/lifelonglearning). This also indicates a deficiency in career guidance as such information is supposed to be given in guiding students on programmes offered in the various institutions of higher learning for them to make informed decisions. The respondents further showed that they did not understand programmes offered in the institute as these where seen as the only LLL in the university. Students who enrolled in the university programmes straight from ' $A$ ' level do not regard themselves as Lifelong learners (see table 4 below) 
Table 6: Students responses on whether they are Lifelong learners

Responses- Yes 49 (43\%), No $65(57 \%)$

A correlation analysis (87.5\%) of whether a student understands LLL against being a LL Learner confirms that students do not understand what LLL is all about. Most first and second year students (57\%) did not consider themselves as lifelong learners.

\begin{tabular}{|l|l|l|}
\hline & & $\begin{array}{l}\text { Are you a LL } \\
\text { Learner? }\end{array}$ \\
\hline Understanding LLL & $\begin{array}{l}\text { Pearson } \\
\text { Correlation }\end{array}$ & $87.5 \%$ \\
\cline { 2 - 3 } & $\mathrm{N}$ & 114 \\
\hline
\end{tabular}

Findings revealed that $45(39.47 \%)$ of the students had no idea what media transmitted LLL in the university, 29(25.43\%) noted that the radio, television are the major transmission media for LLL among students, while the grapevine and peers followed with a 21(18.42\%). The internet and computers was identified by 5 respondents yet most, if not all students are expected to be using the internet in their research and reading. It was interesting to note that reading literature (pamphlets, books, newspapers) fell below the grapevine and peers being identified by $13(11.42 \%)$ students. This finding might be an indicator of lack of literature to explain what lifelong learning is all about for students to read.

Table 7 Lecturers as Lifelong learner

\begin{tabular}{|l|l|l|l|}
\hline \multicolumn{2}{|c|}{} & Frequency & Percent \\
\hline \multirow{2}{*}{$\approx$} & Yes & 54 & $47.4 \%$ \\
\cline { 2 - 4 } & No & 60 & $52.6 \%$ \\
\cline { 2 - 4 }$\approx$ & Total & $\mathbf{1 1 4}$ & $\mathbf{1 0 0 \%}$ \\
\hline \multirow{2}{*}{}
\end{tabular}

About Fifty four (47.4\%) respondents agreed that their lecturers were lifelong learners while $52.6 \%$ disagreed that the lecturers were lifelong learners. The majority's observation that lecturers were not lifelong learners indicates students' misconceptions of lifelong learning. Lecturers in the university are studying for higher qualifications, do research work, consult and interact with new information through workshops and conferences. These lecturers should be role models for students to be lifelong learners, so that the students continue to learn well after acquiring their first degrees, as emulated from lecturers. The 52.6\%'s response shows that students do not understand lifelong learning.

Table 8 Transmission media of LLL in which Community

\begin{tabular}{|l|l|l|}
\hline Transmission Media & Frequency & Percentage \\
\hline None & 44 & $39 \%$ \\
\hline Radio, TV and Internet & 30 & $26 \%$ \\
\hline Grapevine & 15 & $13 \%$ \\
\hline Newspapers, Books and Pamphlets & 8 & $7 \%$ \\
\hline Media and Meetings & 4 & $4 \%$ \\
\hline Peers & 3 & $3 \%$ \\
\hline Church & 3 & $3 \%$ \\
\hline Campaigns & 2 & $2 \%$ \\
\hline Movies & 2 & $2 \%$ \\
\hline Ploughs, Carving tools & 1 & $1 \%$ \\
\hline Banners and Flyers & 1 & $1 \%$ \\
\hline Workshops & 1 & $1 \%$ \\
\hline
\end{tabular}

The $39 \%$, which is the highest response, failed to identify any LLL transmission media while $26 \%$ noted the radio, television and internet as transmitters of LLL followed by the grapevine with $13 \%$. The lowest known transmitters are workshops, banners and flyers with $1 \%$ each and one response identified ploughs, and carving tools as transmitters of LLL. Failure to identify transmitters of LLL is an indicator of misunderstanding LLL. 
Table 9 Knowledge on LLL

\begin{tabular}{|l|l|l|l|l|}
\hline \multirow{2}{*}{ Statement } & \multicolumn{2}{l|}{ TRUE } & \multicolumn{2}{l|}{ FALSE } \\
\cline { 2 - 5 } & Frequency & $\%$ & Frequency & $\%$ \\
\hline LLL is not Government Policy & 54 & $47 \%$ & 60 & $53 \%$ \\
\hline $\begin{array}{l}\text { LLL has no place in a University of } \\
\text { technology }\end{array}$ & 19 & $17 \%$ & 95 & $83 \%$ \\
\hline LLL is Community Based & 82 & $72 \%$ & 32 & $28 \%$ \\
\hline Staff Development is LLL & 79 & $69 \%$ & 35 & $31 \%$ \\
\hline CUT Students are LLL & 80 & $70 \%$ & 34 & $30 \%$ \\
\hline
\end{tabular}

Eighty three percent of respondents noted as false the statement that LLL has no place in a university of technology, 53\% disagreed with the statement that, there was no government policy on LLL. This explains that most students are aware of the existence of a policy on LLL though they believe themselves not to be lifelong learners. The majority were able to categorise staff development and CUTstudents as lifelong learners in this section.

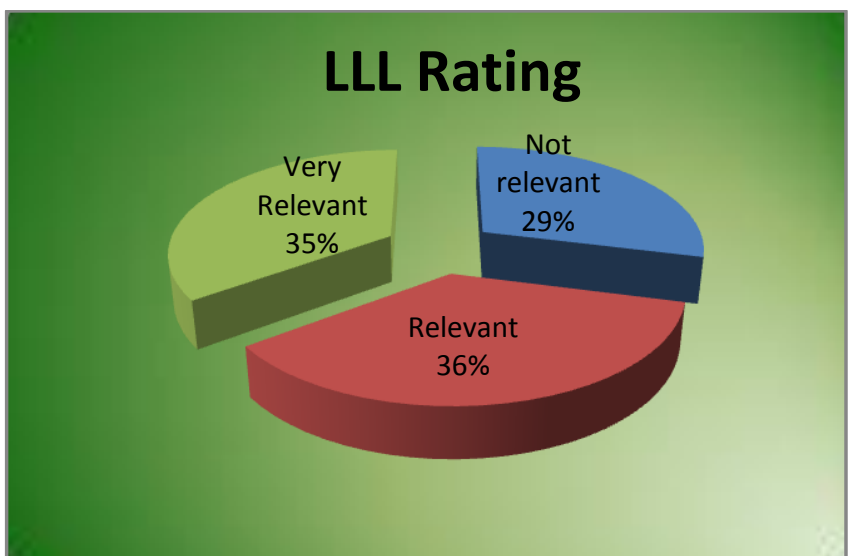

Fig.3 Relevance of LLL in personal development of respondents

Thirty six respondents indicated LLL was relevant, $35 \%$ said it was very relevant while $29 \%$ said it was not relevant. The majority therefore appreciates the role LLL plays in their lives and this may indicate that students are aware of how much they benefited from LLL. Further probing revealed that $50 \%$ of respondents have done LLL and $73.7 \%$ cited the industrial attachment they undertake during the course is LLL. A cross tabulation of the linkage between social mobility and LLL is shown in table 8

Table 10 Social Mobility linked to LLL

A cross tabulation of the linkage between social mobility and LLL is shown below.

\begin{tabular}{|l|l|l|l|l|l|l|l|}
\hline \multirow{2}{*}{\begin{tabular}{l} 
Statement \\
\cline { 3 - 10 }
\end{tabular}} & \multicolumn{6}{|c|}{ How LLL is Linked to Social Mobility } & Total \% \\
\hline $\begin{array}{l}\text { LLL is Linked to } \\
\text { Social Mobility }\end{array}$ & YES & 3 & $\mathbf{2}$ & $\mathbf{3}$ & $\mathbf{4}$ & $\mathbf{5}$ & \\
\cline { 2 - 10 } & NO & 1 & 1 & 2 & 0 & 0 & 88 \\
\hline
\end{tabular}

Key:

1-The learning process has an end once one is employed.

2- Contribute to the success of knowledge economics which leads to development of wealth

3- Education and training are essential to development and high income.

4- Failure to upgrade one's knowledge and skills results in no promotion at the work place.

5- No LLL equals redundancy and out datedness.

6- Social mobility has a ceiling so there is no need to learn continuously.

Eighty eight percent are aware of the link between LLL and social mobility. The identified deficiency is on regarding themselves (university students) as LL Learners.

Rating of University support of $L L L$

Responses were as follows: Very supportive (30) 27.5\%, Supportive (45)41.3\%, Not at all supportive (25)22.9\%, Not aware of LLL (9)8.3\%. 
The university is known to be supportive of lifelong learning as evidenced by setting up an Institute of Lifelong Learning. The institute offers opportunities for skill and knowledge upgrade for professionals and ' $\mathrm{A}$ ' level school leavers.

\section{Students' suggestions on ways of promoting LLL:}

At university level-marketing more on LLL, Community workshops to educate on LLL, Positive integration with all schools in the university so as to naturalise LLL with the prevailing curriculum, Orientation of university students on LLL, Allowing fees to be paid in installments so as to allow more people to study, Accessing computers and the internet and literature on LLL.

\section{National level (Zimbabwe)}

Marketing/ publicising Lifelong Learning, Investing more in computers and internet connectivity for the ordinary Zimbabweans to access information including the rural areas where the majority of the people are located, school curriculum content to include LLL..

\section{Discussion}

The decision to learn is largely personal. Students decide to pursue higher levels of education largely as a personal conviction rather than cohesion by parents, relatives or friends even if parents exert more influence than friends. A significant number of university students (35\%) had an assumption that LLL is for adults as a majority of these students enrolled for university programmes straight from ' $A$ ' level, as indicated in table 3 . The university which offers bridging courses for prospective students to meet entry requirements for university degree programmesmakes it more confusing for straight entry students to visualize themselves as part $f$ a group of LL learners. The belief that LLL must be for those who failed to make it at secondary or high school was quite obvious in this study.

What is the university students' understanding of lifelong learning?

The concept of LLL is not common among people in communities and schools. Students doing bridging Mathematics at the university to qualify for admission into the university programmes and nurses fitted well with university students' conception of LLL. Thus confirming Brahim (2007)'s assertion that Lifelong Learning (LLL) is not understood by many including those in higher offices and academically learned. Whereas Mentkowski (1988:115) refers to LLL as learning to learn, Falk and Dierking (2002:6) call it free learning, meaning therefore that, there are no boundaries to LLL. Students associated LLL with learning in the confines of a classroom/lecture room and this being for adults who missed the opportunity during their school age. This excluded the majority of university students as LLL. Students (35\%) view LLL as a learning programme for a particular group of people, to them it is for teachers and nurses who come to the Institute of Lifelong Learning for a Bachelor of Technology Education and a Bachelor of Science in Nursing Education degree respectively, as well as other adults in the various degree programmes which excluded the lecturers, (see table 4). There seem to be a deficiency in career guidance since the basic skill that teachers and lecturers should impart to learners is the ability and interest to learn and to acquire a new skill requirement, (Wikipedia, online). Students at a university of technology entering university straight from Advanced Secondary level do not regard themselves as lifelong learning yet the area of technology requires constant upgrading through research hence the learning as continuous. There is no way a technology institution cannot emphasise staff development and training and Chinhoyi University has been on the fore front through its teacher and nurse upgrading programme after realizing that education and health are key to national development. The Nziramasanga Commission Report (1999)highlighted that LLL in Zimbabwe is seen as learning without restrictions of time, age and meant for self development.

Brahim (2007)noted that lifelong learning is not understood by many and results showed thatstudents in an institution with an Institute of Lifelong Learning like Chinhoyi University of Technologyhad no clear understanding of lifelong learning. This study showed that students in a university of technology distanced themselves from LLL yet technology changes every now and then.

University students' views (61 out of 114) on the role of LLL confirmed Bengtsson (2009) who noted that skills become obsolete and need to be upgraded. This was also evident in the period when computers were introduced. Technological advancement has required in-servicing and training of employees in the different sectors of economies showing that learning is a lifelong process. The education sector has the role to teach, train and staff develop using different methodologies basing on students needs. It was generally agreed by university students thatLLL played a role in people's lives. Students therefore acknowledge the importance of LLL as shown in figure 1 . 
How are students influenced to be lifelong learners in a university of technology?

Findings revealed that students are influenced to be LL Learners through various media with the majority (26\%) noting the radio, television and internet as transmitters of LLL followed by the grapevine with $13 \%$ and the lowest known transmitters being workshops organized for lecturers. Because of the technological nature of students' programmes, they are forced to research, use e-learning and by so doing they learn new skills as observed by Banta (1993). While lecturers pursuing higher qualifications were considered, the majority (52.6\%) did not classify them as LL Learners therefore the students might not be influenced by the lecturers. Most students however, had no idea what transmits LLL therefore might not have been influenced in any way to be LL learners.

\section{Conclusions}

The study established that the majority of students $(81 \%)$ learnt about LLL when they came to the university and understood in principle, that LLL has no boundaries and it embraces formal, informal and nonformal education as indicated in table 9.However, the same students do not regard themselves as LLL but refer to students enrolled in programmes under the Institute of Lifelong Learning e.g. nurses, teachers as lifelong learners and not students entering university straight from high school('A' level). The role of LLL in people's lives from the students' perspectives was the development of skills, competencies, innovation and creativity. Students also noted that LLL enabled the development of the desire to learn hence, there is need to seriously consider ways of inculcating the desire to learn in people; especially in rural areas were the majority of people are located. Research findings showed that students' LLL are influenced by media especially radios, television, grapevine and their peers. The internet also influenced students although it was identified by only $5 \%$ of the respondents. Literature or print media was not a popular mode in influencing LLL. Students acknowledge the relevance of LLL for personal development and appreciated its existence. The fact that,most students do not perceive themselves and their lecturers to be LLL show that in reality, they do not understand LLL.

\section{Recommendations}

The university should come up with a programme that orients students with issues of LLL so that students understand what LLL is all about and appreciate that they are all lifelong learners in their different programmes and learning modes. This would also help students understand that lecturers are lifelong learners as students studying for higher qualifications and, as lecturers as they do research, prepare for teaching and as they interact with the students during the teaching-learning process.

Most students learnt about LLL when they enrolled at the university showing there is little or no information about LLL in the schools, hence the research recommends for an awareness programme to be carried out in the schools. This programme should aim to reach out to school pupils and communities to develop the desire to learn, read and improve oneself. This approach could include environmental issues e.g. conserving natural resources and waste management to minimize veld fires and disease outbreaks which are major challenges in the Zimbabwean context, for example.

Mainstreaming LLL in the university curriculum and providing reading materials in the library and in departments on LLL as well as other media e.g. more computers and internet for information in different areas. University staff should be role models of LLL and its benefits by informing students on academic achievements of employees so as to inspire students and motivate them to continuously learn.

The media in Zimbabwe (newspapers in different languages, radio, TV, pamphlets and magazines) should embark on programmes that cover lifelong learning issues cutting across social classes so that the desire to learn, to share information and skills is cultivated in the population.

The school system should be such it uses methodologies that instill the desire to learn and to learn without boundaries as in the Chinese proverb, "If you can teach a student for a day; but if you can teach him to learn by creating curiosity, he will continue the learning process as long as he/she lives" In technology areas, learning is not a spectator sport but requires participation all the way, making learning continuous.

\section{References}

[1]. Barret, R.(1998) Liberating the Corporate Soul. Boston. Butterworth- Heinemann

[2]. Bengtsson, (2009) National Strategies for Implementing Lifelong Learning (LLL); AnInternationalPerspective. PASCAL International Observatory, http://www.obs-pascal.com.

[3]. Bourdieu, P. (1986) The forms of capital, in: J.G. Richardson (ed.): Handbook for Theory and Research for the Sociology of Education, 1986, pp... $241-258$

[4]. Brahim, F. A. (2007) Thesis for the Doctor of Philosophy "Medical Students' Perceptions of Lifelong Learning at Indiana University School of Medicine"

[5]. Day, C. (1998) Developing Teachers.New York, Taylor \& Francis Inc.

[6]. Falk, J.H. and Dierking, 1.D. (2002) Lessons without limit: How free- choice learning is transforming education. Walnut Creek, C.A: Altimira Press.

[7]. Fukuyama, F (1999).Social Capital and Civil Society, Prepared for delivery at the IMF Conference on Second Generation Reforms retrieved on $13 / 04 / 12$ 
[8]. Lundmark, C. (2002). Lifelong learning; Bioscience April 2002, Vol. 52. No4 page 325 posted online December 18, 2008

[9]. Mentkowski, M., \& Doherty, A (1984) Abilities that last a lifetime: Outcomes of the Averno experience.AAHE Bulletin, 36(6), 5-6, 11-14.

[10]. Mentkowski, M. (1988), Paths to integrity: Educating for personal growth and professional performance. In S. Srivastva and Associates (Eds.), Executive integrity: The search for high human values in organization life. San Francisco: Jossey-Bass.

[11]. OECD (2004), Policy Brief: Lifelong Learning

[12]. The Education Act of 1987, Harare, Government Printers

[13]. The Presidential Commission of Inquiry into Education and Training; National Report of the Republic of Zimbabwe (1999) "The Nziramasanga Report". Harare, Government Printers

[14]. http://economics.about.com/cs/economicsglossaryh/g/human-capital.html

[15]. http://wikipedia.org/wiki/lifelonglearning 